performing opportunities, let to substantially enrich list of productions of any amateur or professional vocal ensemble. Arrangement lets not only to actualize primary source but also to create original sourcebased musical composition using various expressive means.

Keywords: Russian folk song, Russian song culture, academic chorus, arrangement, setting for chorus, choristic adaptation, preservation of Russian song traditions, Russian composers.

УДК 398.81(571.150)(=161.1):783.8

DOI: $10.32340 / 2414-9101-2021-2-68-72$

Н. А. Яговец

Алтайский государственный институт культуры (Барнаул, Россия) yagovetsna@mail.ru

\title{
СПЕЦИФИКА ХОРОВОЙ АРАНЖИРОВКИ РУССКИХ НАРОДНЫХ ПЕСЕН РЕБРИХИНСКОГО РАЙОНА АЛТАЙСКОГО КРАЯ (РОССИЯ) ДЛЯ СЦЕНИЧЕСКИХ НАРОДНО-ПЕВЧЕСКИХ КОЛЛЕКТИВОВ
}

\begin{abstract}
Аннотация. Исходя из собственного многолетнего опыта вокально-хоровой работы с учебными народно-певческими коллективами Алтайского государственного института культуры (г. Барнаул, Россия) над исполнением произведений местного регионального фольклора, автор раскрывает некоторые теоретико-методические аспекты приспособления народно-песенного материала к вокальным коллективам народного направления различных исполнительских составов, а также характеризует специфику хоровой аранжировки русских народных песен, отражающих стилевые особенности этнопесенной традиции территорий юга Западной Сибири (Ребрихинский район Алтайского края, Россия).
\end{abstract}

Ключевые слова: русская народная песня, хоровая аранжировка, песенный фольклор Ребрихинского района Алтайского края, песенная традиция русских Алтайского края, народно-певческий коллектив.

В деятельности народно-певческих коллективов проблема подбора и расширения репертуара всегда была и остается одной из наиболее актуальных. Руководители коллективов во многом решают ее за счет аранжировки и обработки народных песен. Прикасаясь к произведениям народного песенного творчества, одни рассматривают образцы песенного фольклора, как музыкальнопоэтический материал для претворения своих авторских идей, другие - стараются максимально сохранить оригинал, выполняя редакцию, с целью исполнения песни на сцене практически в подлинном виде или приспосабливают народную песню к исполнительскому составу коллектива путем переложения партитуры. В народно-певческом исполнительстве оба эти подхода получили свое выражение в деятельности различных по художественному направлению коллективов. В основном принято выделять две группы «вторичных» коллективов: «фольклорные, для которых характерно исполнение песенного материала не только в подлинном виде, но и в аранжированном виде и стилизованные, в репертуаре которых преобладает обработанный фольклор и авторские произведения» [1, с. 18]. Репертуар этих коллективов постоянно пополняется самыми различными (по жанру и региональной принадлежности) народными песнями. При их освоении, как правило, требуется соотнесение особенностей фольклорного первоисточника с конкретным исполнительским составом, что и осуществляется в процессе аранжировки.

В современном народно-певческом исполнительстве имеются примеры не всегда удачных решений сценического воплощения фольклорных первоисточников, и, в частности, их аранжировки. Например, аранжировщик или руководитель коллектива, стараясь сделать произведение 
художественно ярким, насыщает песню множеством различных средств выразительности композиторской музыки, что нередко кардинально меняет песню и даже искажает ее до неузнаваемости. В других случаях, руководители, стараясь сохранить фольклорный первоисточник в подлинном виде, допускают небольшие изменения в музыкальном или поэтическом тексте, но не приводят произведение в соответствие с исполнительским составом коллектива, из-за чего песня в сценическом варианте звучит неинтересно и даже карикатурно, а сам коллектив не раскрывает свой исполнительский потенциал.

В последнее время чаще всего при аранжировке фольклорных первоисточников возникает проблема сохранения региональной стилистики и жанровой принадлежности народной песни, другими словами, создания стилевой аранжировки. В связи с этим многие руководители современных народно-певческих коллективах, задаются вопросом: в какой степени возможно творческое вмешательство в фольклорный оригинал и как приспособить фольклорное произведение к исполнительскому составу коллектива, сохранив при этом стилистические особенности песен той или иной традиции? К сожалению, немногие из них успешно решают эту проблему в своих коллективах. Нередко причиной этому является нежелание многих руководителей глубоко изучать региональные песенные традиции, а также анализировать песенные фольклорные образцы, что является необходимым и важным этапом работы в процессе аранжировки народных песен.

Хорошим подспорьем для начинающих руководителей коллективов могут стать теоретикометодические работы по аранжировке, обработке и распеву народных песен «на голоса» ведущих специалистов в области народно-певческого исполнительства: А. Абрамского, М. Медведевой, Л. А. Антиповой, С. Браз. Примером для начинающих аранжировщиков и руководителей коллективов могут послужить творческие работы с фольклорными произведениями М. В. Медведевой, В. А. Царегородцева, В. В. Бакке, Ю. Л. Колесника.

Несмотря на то, что в учебно-методической литературе достаточно полно раскрыты теоретико-методические основы хоровой аранжировки народных песен, в меньшей степени рассматривается специфика аранжировки народных песен узколокальных традиций. В связи с этим специфика хоровой аранжировки русских народных песен Ребрихинского района Алтайского края, раскрываемая автором в настоящей статье, может представлять интерес для руководителей народнопевческих коллективов, в частности данного региона. Автор обобщает опыт хоровой аранжировки песен Ребрихинского района Алтайского края и приводит в пример краткий музыкальный анализ двух народных песен, записанных от потомков переселенцев Алтая из западного и южного регионов России. А также раскрывает специфику, основные требования и этапы хоровой аранжировки народной песни.

«Специфика аранжировки для народно-певческого коллектива обусловлена целым рядом особенностей. Одна из них - это комплексный подход к созданию концертного варианта фольклорного первоисточника, обусловленный его синкретизмом - соединением поющих, танцующих и играющих на различных инструментах участников при взаимозаменяемости их в творческо-исполнительском процессе» [2, с. 7]. Также необходимо возможно полнее раскрывать жанровую природу песни, учитывая, что для различных жанров характерна в разной степени развитая хоровая партитура. Особенно важно при хоровой аранжировке фольклорного первоисточника учитывать местные исполнительские традиции и стилевые особенности многоголосия. «Кроме того, известно, что народная песня каждый раз звучит по-разному даже при ее исполнении одним и тем же составом, что объясняется импровизационной природой русского традиционного песенного исполнительства. Это предполагает гибкий, творческий подход к процессу аранжировки» [2, с. 7].

В процессе аранжировки народных песен происходит творческое вмешательство в фольклорный первоисточник. Чтобы не допустить искажения фольклорного первоисточника необходимо соблюдать следующие требования: сохранить: основной напев, последовательность опорных тонов, основные функции голосов, ладогармонические особенности, метроритмические основы, форму, стилистическое единство. «При аранжировке позволительно лишь некоторое вмешательство в оригинал, необходимое для приспособления произведения к новым техническим условиям» $[2$, с. 8]. Приступая к творческой работе с первоисточником, аранжировщик, прежде всего, должен 
глубоко изучить музыкальный и поэтический материал, изучить музыкально-стилистические и исполнительские особенности песен той региональной певческой традиции, к которой относится выбранное для аранжировки произведение. На следующем этапе работы определяются способ и приемы аранжировки, исходя из того или иного вида творческой деятельности: редактирования, облегченного изложения партитуры, переложения и других. Сам процесс обновления фольклорного первоисточника может включать такие виды деятельности, как упорядочение голосоведения, распределение певческой нагрузки между хоровыми партиями, организация музыкального материала первоисточника, подсочинение или изъятие голосов.

В каждом отдельном случае аранжировщик, ставя перед собой определённые задачи, выбирает необходимые виды работы. При этом всегда главным и определяющим должно быть сохранение «народности» песни. Таким образом, в процессе творческого преобразования фольклорного первоисточника важно учитывать музыкально-стилистические, поэтические и исполнительские особенности песни. Так, музыкальная стилистика народной песни раскрывается в особенностях ее мелодики (здесь рассматривается характер движения мелодических линий напева и подголосков), особенностях многоголосия, формообразования, ладовой и метроритмической организации песен.

Раскроим особенности аранжировки фольклорного первоисточника на примере песенных образцов, собранных автором в Ребрихинском районе Алтайского края. Придерживаясь основных этапов аранжировки, прежде всего, рассмотрим музыкальную стилистику песенных образцов данного района. Репертуар Ребрихинского района представлен как песнями старожильческих певческих групп (казачьими песнями и песнями кержаков), так и песнями позднепоселенцев - украинцев и переселенцев из среднерусских губерний. «Песенный репертуар Ребрихинского района представлен разными жанрами - лирическими, историческими, хороводными, шуточными, свадебными песнями» [3, с. 57]. Рассматривая музыкально-стилистические особенности песен, можно отметить признаки, характеризующие певческие традиции этнокультурных групп Алтайского края. Например, к стилевым признакам многоголосия песенных образцов района относится преобладание параллельных терций при ведущей роли нижнего голоса. Такой тип русского песенного многоголосия называется ленточным. «Суть ленточного типа многоголосия состоит в том, что голоса движутся параллельно, в основном в терцию, временами образуя квинтовые, квартовые и иные созвучия, а также иногда сливаются в унисон» [4, с. 233]. Склад многоголосия, основанный на ленточном изложении напева (преимущественно параллельными терциями) является «особенностью старожильческого пласта сибирского фольклора, в котором представлены в основном жанры лирических и хороводных песен» [5, с. 167].

«Для некоторых образцов характерна контрастная полифония с присущей мелодической и ритмической самостоятельностью каждого голоса, витиеватостью голосов, например, свадебная песня "Верея, наша вереюшка“ [3, с. 58]. Для песен Ребрихинского района также характерны декламационный, умеренный и широкий (реже) типы мелодического распева, чаще всего волнообразный тип мелодического движения. «Для песен характерны также словообрывы, цезуры, паузы, которые членят музыкальную мысль и падают на середину слова» [3, с. 58]. В шуточных песнях и песнях позднего пласта часто встречается синкопированный ритм. Для песен южнорусских переселенцев характерны триоли, мелкие длительности, глиссандо на конце фраз. Для песен Ребрихинского района характерно исполнение в низком регистре, в основном в медленном или умеренном темпах, при этом запев отличается более скорым темпом и метроритмической свободой.

Остановимся более подробно на двух песенных образцах: лирической песне, записанной в селе Ворониха Ребрихинского района Алтайского края «Ой, куда сия дорога» и хороводной круговой песне, записанной в селе Ребриха Алтайского края от переселенки из Курской губернии, приехавшей на Алтай в начале XX века совсем маленькой со своей семьей. Песни, которые удалось записать от исполнительницы, были услышаны ей от ее мамы.

Первый образец был записан в двухголосном варианте от женского ансамбля. Для песни характерны: функциональное двухголосие с элементами ленточного движения голосов в терцию и октавными унисонами в середине и конце строф, ритмическая самостоятельность голосов в окончании строф. Ладовая организация песни раскрывается в квартовой переменности устоев, 
минорном наклонении с седьмой низкой ступенью. В песне сочетаются слоговой и умеренный распев поэтического текста, широкие скачки с последующим заполнением и волнообразное движение мелодики с опеванием устоев в окончании строф. Особенно выразительна запевная часть песни, охватывающая полный диапазон основного напева и насыщенная широкими скачками, мелизмами и глиссандо.

Представим вариант переложения партитуры данной песни на двухголосный смешанный состав. В данном случае аранжировки возможно сохранение тональности и фактуры первоисточника. Партия нижнего женского голоса, в которой проходит запев и основной напев, передается прямым способом партии мужских голосов, что обусловлено соответствием тесситуры звучания нижнего женского голоса диапазону партий первых баритонов или вторых теноров. Такое низкое звучание женских голосов является характерной особенностью исполнения песен Алтайского края. Партия же верхнего голоса первоисточника удобна для исполнения партией альтов.

Предложим другой вариант переложения песни «Ой, куда сия дорога» для полного четырёхголосного смешанного состава. В этом случае запев может остаться у альтовой партии, основной же напев распределиться между альтовой группой и партией верхнего мужского голоса, что связано с широким диапазоном мелодии основного напева. Таким образом, партии мужских голосов составляются на мелодическом материале партии альтовой группы, а также путем подсочинения звуков, удобных по тесситуре мужским голосам и не противоречащим гармоническим особенностям песни. При составлении партии альтов возможно использовать прием комбинирования мелодических оборотов основного напева и верхнего подголоска. Верхний подголосок хорошо прозвучит в исполнении партией сопрано. С целью создания удобных тесситурных условий для женских голосов партитуру необходимо транспонировать на большую секунду вверх.

Более сложный вариант хоровой аранжировки рассмотрим на примере хороводной песни «Я люта была», записанной в одноголосном варианте. Музыкально-стилистический анализ первоисточника позволил выявить следующие особенности песни: узкообъемный лад мажорного наклонения с устоем на втором нижнем звуке звукоряда, напев начинается с середины звукоряда и развивается в объеме квинты с захватом седьмой ступени внизу звукоряда. Для песни также характерен умеренный слоговой распев, пунктирный ритм вначале строфы и последующее более ровное ритмическое движение с чередованием восьмых и четвертных длительностей. Характерной исполнительской особенностью песни являются такие средства выразительности, как словоразрывы и словообрывы, которые необходимо сохранить при аранжировке песни.

Раскроем особенности создания аранжировки песни «Я люта была» для женского трехголосного состава путем усложнения партитуры первоисточника и подсочинения голосов. Так, в процессе создания подголосков использовался прием мелодического и ритмического варьирования основного напева. В результате создания многоголосной партитуры два верхних голоса (основной напев и подголосок) развиваются в едином диапазоне, переплетаясь друг с другом и сливаясь в унисон в окончаниях фраз и в моменты словоразрыва. Нижний подголосок, созданный также путем варьирования основного напева, охватывает лишь нижние звуки звукоряда, периодически опускаясь на седьмую и пятую ступени лада. При этом основной напев, располагаясь в верхнем голосе, ясно прослушивается, а досочинённые подголоски, предназначенные для исполнения нижними голосами, отличаются большой ритмической самостоятельностью, гармонически обогащают песню. Такой вариант многоголосного исполнения песни выразительно раскрывает ее жанровую природу, а также обусловлен тем, что музыкально-стилистические особенности фольклорного первоисточника позволяют отнести песню к западнорусской песенной традиции.

В заключение хочется отметить, что в настоящее время музыкально-сценическое воплощение музыкального фольклора достигло большого размаха. Это стимулирует многих руководителей народно-певческих коллективов к написанию оригинальных хоровых аранжировок и созданию неповторимого собственного репертуара. При этом каждый аранжировщик должен понимать, что любое прикосновение к фольклорному первоисточнику требует, прежде всего, бережного обращения с оригиналом, сохранения региональной и жанровой принадлежности песни, что, к сожалению, не всегда соблюдается. Одной из причин является недостаточная освещенность вопроса 
хоровой аранжировки русских народных песен локальных песенных традиций в современной научно-методической литературе. В свою очередь примеры и анализ аранжировок разнорегиональных песенных образцов помогли бы многим руководителям народно-певческих коллективов в работе с музыкальным фольклорным материалом.

\title{
Список литературь
}

1. Медведева, М. В. Творческое освоение произведений фольклора в учебной практике народно-певческого отделения вуза // Музыкальное образование в контексте культуры: народнопевческое образование на пороге XXI века : матер. Всерос. конф. (Москва, 1998 г.). - Москва : РАМ им. Гнесиных, 1999. - С. 15-25.

1. Аранжировка и обработка как творческий процесс обновления фольклорного первоисточника: учеб.-метод. пособие / авт.-сост. : О. С. Щербакова, Н. А. Яговец, С. В. Леонидов. - Барнаул : Изд-во Алтайской гос. академии культуры и искусств, 2005. - 96 с.

2. Яговец, Н. А. Песенные традиции Ребрихинского района Алтайского края и их сохранение в процессе образовательной подготовки руководителей народного хора // Учёные записки (Алтайская государственная академия культуры и искусств). - 2020. - № 4. - С. 56-60.

3. Щербакова, О. С. Фольклорно-этнографические и песенные традиции русских Алтая : учеб. пособие : [в 2 ч.]. - Барнаул : Изд-во Алтайской гос. академии культуры и искусств, 2005. Ч. $1 .-181 \mathrm{c}$.

4. Щуров, В. М. Стилевые основы русской народной музыки. - Москва : Московская гос. консерватория им. П. И. Чайковского, 1998. - 464 с. : нот.

Natalia A. Yagovets

Altai State Institute of Culture (Barnaul, Russia) yagovetsna@mail.ru

\section{SPESIFICS OF CHOIR ADAPTATION OF RUSSIAN PEOPLE'S SONGS COLLECTED FROM REBRIKHINSKII DISTRICT OF ALTAI KRAI (RUSSIA) FOR STAGE PEOPLE'S SINGING ENSEMBLES}

\begin{abstract}
Based on long-term experience of vocalic-choir work with academic ensembles of the Altai State Institute of Culture (Barnaul, Altai Krai, Russia) on pieces of local music folklore, the author discloses some theoretic and instructional aspect of adaptation of people's song material to people's vocal ensembles of various team compositions, and also describes specifics of choral arrangement of Russian people's songs that reflect stylistic peculiarities of ethnic song tradition of Russian areas of the South of Western Siberia (Rebrikhinsky District of Altai Krai, Russia).

Keywords: Russian folk song, adaptation for choir, song folklore of Rebrikhinsky District of Altai Krai, song tradition of Russians of Altai Krai, people's-singing ensemble.
\end{abstract}

